\title{
Corticosteroids and cardiopulmonary bypass: Empiricism or science?
}

\author{
Ali Fatehi Hassanabad, MD, MSc, and Paul W. M. Fedak, MD, PhD, FRCS(C)
}

\author{
From the Section of Cardiac Surgery, Department of Cardiac Science, Cumming School of Medicine, University \\ of Calgary, Libin Cardiovascular Institute of Alberta, Calgary, Alberta, Canada \\ Disclosures: Authors have nothing to disclose with regard to commercial support. \\ Received for publication Sept 26, 2018; accepted for publication Sept 27, 2018; available ahead of print Oct 26, \\ 2018. \\ Address for reprints: Paul W. M. Fedak, MD, PhD, FRCS(C), C880, 1403-29 St NW Calgary, Alberta, Canada, \\ T2N 2T9 (E-mail: paul.fedak@gmail.com). \\ J Thorac Cardiovasc Surg 2019;157:270-1 \\ $0022-5223 / \$ 36.00$ \\ Copyright (c) 2018 by The American Association for Thoracic Surgery \\ https://doi.org/10.1016/j.jtcvs.2018.09.072
}

Artificial cardiopulmonary bypass (CPB) has facilitated the practice of cardiac surgery. CPB technology is safe and effective, but complications remain. CPB induces a systemic inflammatory response to the artificial circuit. Inflammation may play a key role in mediating adverse postoperative events and complications. These can range from subclinical reversible tissue injuries to profound irreversible multiorgan dysfunction syndrome. To mitigate such effects, the perioperative use of corticosteroids has been proposed. Steroids may prevent CPB-induced systemic inflammation and improve clinical outcomes. A recent meta-analysis investigated the effects of prophylactic steroids in patients undergoing cardiac surgery with CPB. The study was unable to define a clear protective effect on operative mortality. ${ }^{1}$ These inconclusive results were also observed in a previous study also designed to assess the impact of steroids on outcomes after CPB. ${ }^{2}$ As such, the debate continues as to the merits of providing prophylactic corticosteroids to prevent inflammation as a consequence of artificial CPB.

Empiricism is the idea that all valuable information can be derived from observations and experiences. As surgeons, we continue to learn and improve by our direct patient care encounters. As compared with the practice of medicine, evidence-based decisions in surgery are challenged by numerous obstacles in performing rigorous clinical trials. ${ }^{3}$ Empiricism provides the incentive for clinical improvements, but the impact of a new intervention is best determined through robust and highly controlled clinical studies. The rationale for use of perioperative steroids in cardiac surgery is mostly empiric to date.

To that end, Gao and colleagues ${ }^{4}$ examined the effects of preoperative inhaled budesonide on pulmonary injury after $\mathrm{CPB}$. These investigators designed a prospective, doubleblinded, randomized controlled trial that is notable for

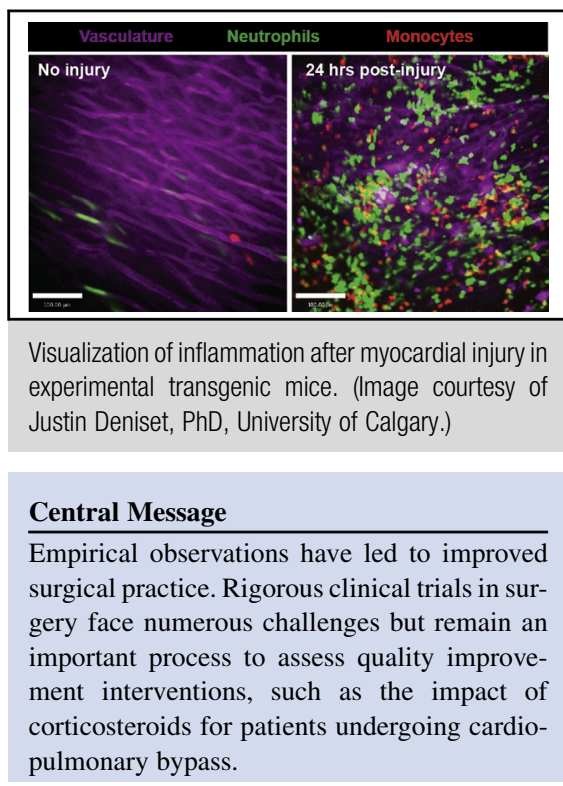

See Article page 272. considering inhaled steroids with local effects, as previous research has focused on the systemic use of steroids, which did not promote recovery from lung injury post-CPB. ${ }^{5,6}$ The study examines both clinical outcomes and inflammatory biomarkers in specific tissue compartments (blood and bronchoalveolar lavage samples) to assess the direct influence on inflammatory parameters. Ventilation parameters are used to explore the effects of budesonide on gas exchange and lung compliance. This simple inhaled steroid approach was shown to be capable of reducing local inflammation in tissues and improving early postoperative measures of lung performance. The effects on hard clinical outcomes remain to be determined, but the data are encouraging. As in all clinical studies, limitations should be noted. This pilot randomized controlled trial excludes patients with any preoperative lung pathology. These are the patients who would most benefit from the proposed intervention. The clinical relevance of the measured parameters of inflammation with important clinical outcomes is not yet validated. It is also unclear how clinically feasible this approach may be in a real-world setting.

Using steroids in the setting of cardiac surgery has been controversial since $\mathrm{CPB}$ was observed to cause 
inflammation. To date, empiricism has dominated the use of perioperative steroids in cardiac surgery. More evidence-based clinical studies are needed to support its optimal use. This work is a step in that direction.

\section{References}

1. Dvirnik N, Belley-Cote EP, Hanif H, Devereaux PJ, Lamy A, Dieleman JM, et al. Steroids in cardiac surgery: a systematic review and meta-analysis. Br J Anaesth. 2018;120:657-67.

2. Carrel T, Englberger L. Steroids and cardiopulmonary bypass: a never-ending story. Semin Thorac Cardiovasc Surg. 2017;29:45-6.
3. McCulloch P, Taylor I, Sasako M, Lovett B, Griffin D. Randomised trials in surgery: problems and possible solutions. BMJ. 2002;324:1448-51.

4. Gao W, Li N, Jin ZH, Lv XQ, Cui XG. Effect of preoperative inhaled budesonide on pulmonary injury after cardiopulmonary bypass: a randomized pilot study. $J$ Thorac Cardiovasc Surg. 2019;157:272-84.

5. Oliver WC Jr, Nuttall GA, Orszulak TA, Bamlet WR, Abel MD, Ereth MH, et al. Hemofiltration but not steroids results in earlier tracheal extubation following cardiopulmonary bypass: a prospective, randomized double-blind trial. Anesthesiology. 2004;101:327-39.

6. Sobieski MA II, Graham JD, Pappas PS, Tatooles AJ, Slaughter MS. Reducing the effects of the systemic inflammatory response to cardiopulmonary bypass: can single dose steroids blunt systemic inflammatory response syndrome? ASAIO J. 2008:54:203-6. 